\title{
Free Fatty Acids Esterification on Palm Oil Sludge using Zirconia-supported Indonesian Natural Zeolite as Heterogeneous Catalyst
}

\author{
ARIF HIDAYAT ${ }^{1 *}$ and BACHRUN SUTRISNO ${ }^{1}$ \\ ${ }^{1}$ Chemical Engineering Department, Universitas Islam Indonesia, Yogyakarta 55584, Indonesia. \\ ${ }^{*}$ Corresponding author E-mail: arif.hidayat@ uii.ac.id \\ http://dx.doi.org/10.13005/ojc/340531
}

(Received: June 05, 2018; Accepted: August 22, 2018)

\begin{abstract}
Biodiesel production has been attracted more intense study because of the growing interest in finding the alternative renewable energy resources. Commonly biodiesel production is produced using refined vegetable oils as feedstocks which catalyzed by a homogeneous catalyst. However, the homogeneous catalyst has many disadvantages such as complex products separation and environmentally problem. In this research, the esterification of Palm Oil Sludge (POS) using zirconia supported Indonesian natural zeolite as a heterogeneous catalyst was studied. The POS is low feedstock price and available abundantly. The catalysts were analyzed in term of porosity analysis (Gas Sorption Analysis method), XRD and FTIR. The FFAs conversion as high as was $84.2 \%$ achieved at following reaction conditions: $2 \mathrm{~h}$ reaction time, $65^{\circ} \mathrm{C}$ reaction temperature, $1: 10$ POS to methanol mole ratio, and catalyst amount 10 wt.\% of POS. The FFA conversion was decreased after three consecutive of esterification reaction.
\end{abstract}

Keywords: Esterification, Sludge palm oil, Biodiesel, Natural zeolite, Free fatty acids, Sulfated zirconia

\section{INTRODUCTION}

The biodiesel development as the sources of alternative renewable energy to substitute diesel fuel from crude oil has gained more attention in the last few decades due to the decreasing of fossil fuel reserves and environmental concern. It has several benefits such as biodegradable, environment friendly, and less toxic. Biodiesel can be generated from animal fat or vegetable oil through a transesterification reaction. Conventionally, a base catalyst, such as potassium and sodium hydroxides, is used to catalyze the transesterfication in biodiesel production. The transesterification esterification reactions are expressed in Figure 1.

Many types of vegetable oil sources such as soybean ${ }^{1}$, corn $^{2,3}$, palm oil ${ }^{4,5}$, coconut ${ }^{6}$, sunflower ${ }^{7}$, canola ${ }^{8}$, and bran $^{9}$ can be utilized as feedstocks to produce biodiesel. However, the utilization of vegetable oil as a feedstock for biodiesel production 
has many drawbacks i.e. less economic prospect and impractical due to high feedstock price and competition as a food supply ${ }^{10}$. To solve the problem, low-grade oil or non-edible oil which has low price can be used as biodiesel feedstocks ${ }^{11}$. This type of feedstocks contains high free fatty acids (FFAs) so that lead to saponification when using base catalysts. To overcome the problem, the acid catalysts should be applied for converting FFAs to biodiesel when using these feedstocks.

\begin{tabular}{|c|c|c|c|c|}
\hline $\mathrm{CH}_{2} \mathrm{COOR}_{1}$ & & base & $\mathrm{R}_{1} \mathrm{COOCR}$ & $\mathrm{CH}_{2} \mathrm{OH}$ \\
\hline | & & catalyst & & \\
\hline $\mathrm{CHCOOR}_{2}$ & $+3 \mathrm{ROH}$ & $\Leftrightarrow$ & $\mathrm{R}_{2} \mathrm{COOCR}+$ & $\mathrm{CHOH}$ \\
\hline $\begin{array}{l}\mathrm{CH}_{2} \mathrm{COOR}_{3} \\
\text { Triglycerides }\end{array}$ & Alc & & $\begin{array}{r}\mathrm{R}_{3} \mathrm{COOCR} \\
\text { Biodiesel }\end{array}$ & $\begin{array}{l}\mathrm{CH}_{2} \mathrm{OH} \\
\text { glycerol }\end{array}$ \\
\hline
\end{tabular}

Fig. 1. Transesterification reactions

In 2017, the palm oil industries in Indonesia has generated 2,4 million tons of palm oil which means generating low-grade oil in large amounts such as palm oil sludge (POS) as wastes ${ }^{12}$. The POS has a large amount of free fatty acids (FFAs) that be reacted with an alcohol using acid catalyst to form biodiesel. Utilization of POS can be replaced the refined vegetable oils feedstocks in order to enhance the production of biodiesel potential economically.

Biodiesel can be synthesized by esterification reactions of FFAs on POS with an alcohol to produce methyl esters and water. Sulfuric acid, as well as hydrochloric acid or nitric acid, are commonly employed as homogeneous catalysts to accelerate the reaction. Fig. 2. is expressed the esterification reactions for producing esters or biodiesel.

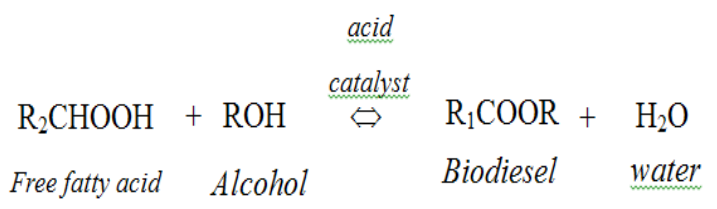

Fig. 2. Esterification reactions

The esterification reactions have many limitations, i.e. requires advances process for purification of products, further separation of catalyst, and furthermore the homogeneous catalysts are not reusable ${ }^{13}$. In order to eliminate the limitations related to using homogeneous catalysts, the heterogeneous catalyst is applied in biodiesel production. The heterogeneous catalysts offer several benefits such as produce fewer amounts of chemical waste and wastewater, not necessary advances process separation, has a hydrophobic surface, and less corrosion. Many studies have been reported the using of heterogeneous catalyst for biodiesel production, such as sulphated zirconia $\left(\mathrm{SO}_{4}{ }^{2-} / \mathrm{ZrO}_{2}\right)^{14-16}$, zeolite ${ }^{17,18,19,20}$, Lanthanum $\left(\mathrm{La}^{3+}\right)$ and HZSM-521, Natural clay ${ }^{22-24}$, Amberlyst $15^{25}$, alumina $\left(\mathrm{Al}_{2} \mathrm{O}_{3}\right)^{26}$, silica ${ }^{27}$, hydroxyapatite ${ }^{28}$, Tungsten supported titania-silica composite ${ }^{29}$, Tin oxide ${ }^{30}$, niobic $^{31}$, SBA-15 $5^{32,33}$, Titania ${ }^{34}$ and biomass waste biomass wastes $^{10,12,35-37}$

However, most of the heterogeneous catalysts as reported have complex preparation steps and expensive synthesis routes. The heterogeneous catalysts should be synthesized by simple preparation steps, available abundantly and low in price to reduce the catalyst production cost. Zeolite is an aluminosilicate natural mineral which has a crystalline framework three-dimensional structure to form pores with uniform size. Zeolite has been applied in many industrial applications, such as adsorbent in wastewater treatment, molecular sieve, catalyst, etc. The study related to the Indonesia natural zeolite application for biodiesel production as a solid catalyst is still limited. The esterification reactions of FFAs with methanol, using zirconia supported on Indonesia natural zeolite, were an investigation in this research. The natural zeolite catalyst activity to convert FFAs to biodiesel was tested in terms of the reaction temperatures, POS to methanol mole ratio, catalyst amounts and reaction time. The catalyst reusability for consecutive reactions was also investigated in this work.

\section{EXPERIMENTAL}

\section{Preparation of Catalyst}

Prior to use, natural zeolite collected from Gunung Kidul province, Indonesia was crushed to obtain small particle with a size of 200 mesh. Then, to remove the organic impurities from the internal pores, the zeolite was activated by mixing with sulfuric acid $0.5 \mathrm{~N}$ solutions. The activation was performed by heating the solution containing natural zeolite at $80^{\circ} \mathrm{C}$ for $4 \mathrm{~h}$ while vigorous stirring. Subsequently, the activated natural zeolite was separated from solutions by filtration and rinsed with distilled water until the wash water free from sulfate ions. Then, the activated natural zeolite was dried in an oven 
to remove remaining water from internal pores for overnight at $110^{\circ} \mathrm{C}$. The catalyst was prepared by impregnation of Zirconia metals on the activated natural zeolite. The catalyst synthesis procedure is described as follows: (i) $10 \mathrm{gr}$ of Zirconium (IV) oxychloride octahydrate $\left(\mathrm{ZrOCl}_{2} \cdot 8 \mathrm{H}_{2} \mathrm{O}\right)$ was added into $100 \mathrm{~mL}$ distilled water and mixed well, (ii) followed by the addition of activated natural zeolite into the $\mathrm{ZrOCl}_{2} \cdot 8 \mathrm{H}_{2} \mathrm{O}$ salt solutions, (iii) the mixture was agitated at $60^{\circ} \mathrm{C}$ for $8 \mathrm{~h}$, after completing the impregnation procedure, the mixture was dried to remove remaining water in an oven at $130^{\circ} \mathrm{C}$ for 8 hours. Finally, the sample was calcined in a furnace at $550^{\circ} \mathrm{C}$ for 3 hours.

The BET (Brunauer-Emmet-Teller) method was applied to determine specific surface area of catalysts. BET method was based on the physical adsorption of nitrogen between relative pressures (P/P0) of $0.05-0.35$ at $77 \mathrm{~K}$. The surface functional groups were characterized using Fourier Transform Infrared (FT-IR) spectroscopy which performed in the wavelength number between ranges of $400-4000 \mathrm{~cm}^{-1}$. The materials crystalline structures were determined using $X$-Ray Diffraction at operating condition $40 \mathrm{kV}$ and $40 \mathrm{~mA}$ with $2 \theta$ measurements between the ranges of $5^{\circ}$ to $80^{\circ}$.

\section{Activity Test}

Esterification of FFA on POS was run in a $250 \mathrm{~mL}$ two-neck flat-bottom flask as a batch reactor. A hot plate equipped a magnetic stirrer was used to stir the reactant at the batch reactor. The batch reactor was connected to a condenser and equip with a thermometer to indicate reaction temperature. Firstly, a certain amount of catalyst was mixed to a known volume of methanol and raised to the selected temperature under continuous stirring. Subsequently, POS was poured slowly into the reactor. The reaction was conducted till the completion of the reaction ( $2 \mathrm{~h}$ reaction time). The reaction conditions were varied in terms of POS to methanol mole ratio, catalyst amount, and reaction temperature to obtain optimum conditions. When the reaction was completed, the biodiesel product was separated from the catalyst by filtration. The product mixture was put into a separating funnel and kept at room temperature for overnight, after which two liquid phases appeared. The upper layer consists of the biodiesel product, and whiles the remaining methanol and water were in the bottom. The acid value $(\mathrm{AV})$ of the upper layer was measured by titration method. The AV is described as the weight of potassium hydroxide in mg required to neutralize $1 \mathrm{~g}$ of oil contains of the FFAs. Initially, the samples were heated in the oven at $110^{\circ} \mathrm{C}$ in order to eliminate the remaining of methanol and water. The titration technique was carried out by using $0.1 \mathrm{M}$ $\mathrm{KOH}$ solution as the titrant, while phenolphthalein as indicator. The volume of alkaline solution consumed was noted, and the AV of sample was determined using Equation 1.

$$
A V=\frac{V \cdot 0.1 .56 \cdot 1}{m}
$$

where $A V$ is the sample acid value (mg $\mathrm{KOH} / \mathrm{g}$ ), $\mathrm{V}$ is the $\mathrm{KOH}$ solution volume used in the titration $(\mathrm{mL}), 0.1$ is the $\mathrm{KOH}$ solution concentration $(\mathrm{mol} / \mathrm{L}), \mathrm{m}$ is the sample weight $(\mathrm{g})$, and 56.1 is the $\mathrm{KOH}$ molecular weight. The FFAs conversion (X_F) was calculated using Equation 2.

$$
X_{F}(\%)=\left(1-\frac{\text { acid value after reaction }}{\text { initial acid value }}\right) \times 100
$$

The catalyst reusability test was performed under the same optimum reaction conditions in the experiment with the fresh catalyst. The reused catalysts were washed with $n$-hexane and dried in an oven at $100^{\circ} \mathrm{C}$ for $4 \mathrm{~h}$ prior to reuse. Three consecutive of esterification reactions were carried out to evaluate the catalyst reusability.

\section{RESULTS AND DISCUSSION}

\section{Catalyst Characterization}

The crystalline structure of activated natural zeolite and zirconia catalyst were presented in Fig. 3 (a) and (b). As presented in Fig. 3 (a), the activated natural zeolite diffraction peaks shows the characteristics of mordenite and clipnotile zeolites which appears at $2^{\circ} \theta=9.76(200), 19.68$ (4 0 0), 22.38 (1 5 0), 25.78 (2 0 2), 27.68 (5 11 1), and 30.05 (1 5 1). In the other hand, the catalyst presents characteristic peaks of zirconia oxide at $2^{\circ} \theta=30.47$ (2 21 ), 30.87 (1 1 1 1) and 50.55 (2 20$)$. It can be observed that the catalysts retained the ordered structure. The intensity decreasing could be attributed the loading of zirconia on the solid surface. The shifting of diffraction peaks corresponds to the cell parameters due to the shrinkage of pores framework after the impregnation of zirconia. 


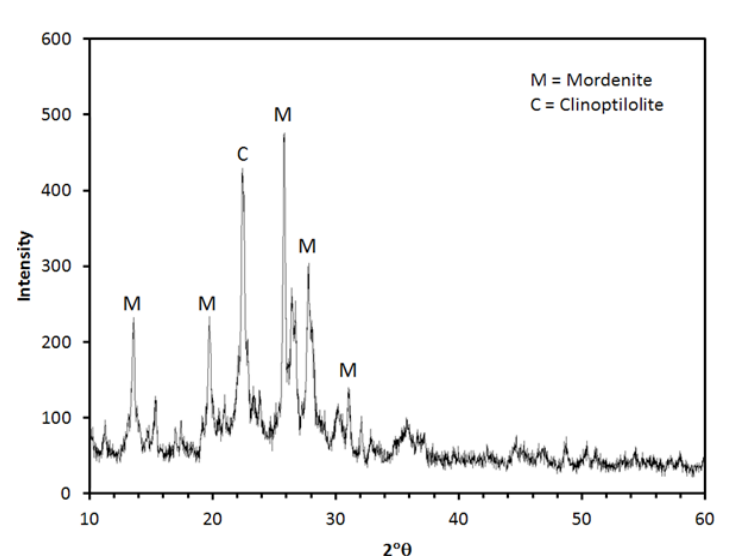

(a)

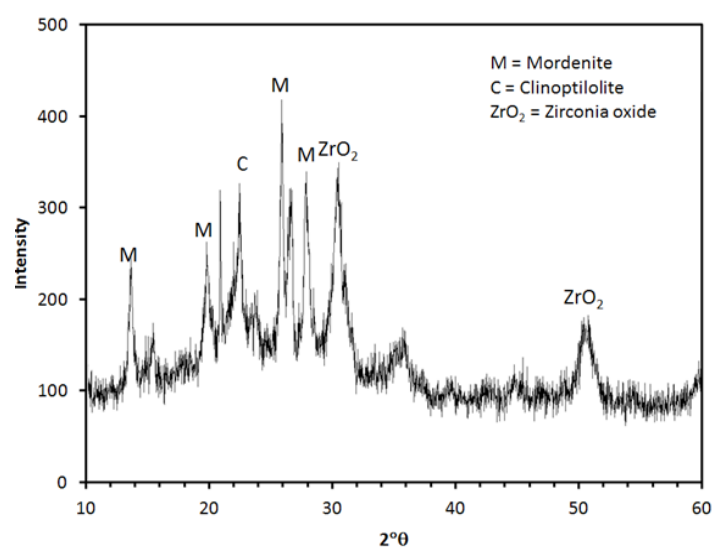

(b)

Fig. 3. The XRD characteristics of activated natural zeolite and zirconia catalyst

The activated natural zeolite and zirconia catalyst $\mathrm{N}_{2}$ adsorption-desorption isotherms were exhibited in Fig. 4 As presented in Fig. 4, the activated natural zeolite as well as zirconia catalyst exhibited the type IV of isotherms with $\mathrm{H} 4$ hysteresis loops which associated with the characteristic of mesoporous materials with narrow slit-like pores, internal voids of irregular shape while the pore size distribution is broad. A decrease in the volume of nitrogen adsorption indicates a reduction in surface area after zirconia impregnation on the activated natural zeolite.

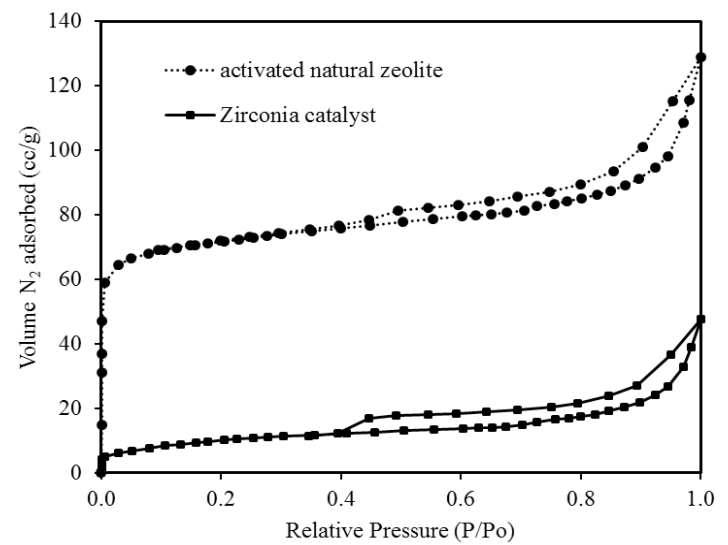

Fig. 4. The activated natural zeolite and zirconia catalyst $\mathrm{N}_{2}$ adsorption-desorption isotherms

The BET surface area, pore volume, and average pore size diameter of the activated natural zeolite and zirconia catalyst are shown in Table 1. The activation process was successful in increasing of the natural zeolite surface area from 177.542 to $213.421 \mathrm{~m}^{2} \cdot \mathrm{g}^{-1}$. The pore volume also increased from 0.2005 to $0.0 .2107 \mathrm{~cm}^{-1}$. The increasing of surface area and pore volume is due to the removal of impurities on the natural zeolite internal pores by activation process using chemical treatment. Furthermore, the impregnation of zirconia metal as active sites would reduce the surface area to 115.348 $\mathrm{m}^{2} \cdot \mathrm{g}^{-1}$ as well as pore volume $\left(0.07892 \mathrm{~cm} \cdot \mathrm{g}^{-1}\right)$. The average pore diameter widened from 3.74 to 8.28 $\mathrm{nm}$ after impregnation of Zirconia metal on the surface of the catalyst. An increase in mean pore diameter will facilitate accessing of free fatty acid compounds to penetrate into the internal pores of catalyst materials.

The successful of incorporated of zirconia metals on catalyst surface was determined using Energy Dispersive X-ray Spectroscopy (EDS) to calculate elemental composition. Before impregnation step, the activated natural consist of $\mathrm{Na}(0.62 \% \mathrm{w} / \mathrm{w})$, $\mathrm{Al}(6.13 \% \mathrm{w} / \mathrm{w})$ and $\mathrm{Si}(27.83 \% \mathrm{w} / \mathrm{w})$ respectively. While after impregnation, the zirconia catalyst

Table 1: Physicochemical characterics of samples

\begin{tabular}{lccc}
\hline Sample & $\begin{array}{c}\text { BET surface area } \\
\left(\mathrm{m}^{2} \mathrm{~g}^{-1}\right)\end{array}$ & $\begin{array}{c}\text { Average pore size } \\
\text { diameter }(\mathrm{nm})\end{array}$ & $\begin{array}{c}\text { total pore volume } \\
\left(\mathrm{cm}^{3} \mathrm{~g}-1\right)\end{array}$ \\
\hline Natural zeolite & 177.542 & 2.26 & 0.2005 \\
Activated natural zeolite & 213.421 & 3.74 & 0.2107 \\
Zirconia catalyst & 115.348 & 8.28 & 0.07892 \\
\hline
\end{tabular}


containing $\mathrm{Na}$ (6.13\% w/w), $\mathrm{Al}(6.13 \% \mathrm{w} / \mathrm{w}), \mathrm{Si}(6.13 \%$ $\mathrm{w} / \mathrm{w})$ and $\mathrm{Zr}(6.13 \% \mathrm{w} / \mathrm{w})$. The FT-IR spectra for both activated natural zeolite and zirconia catalyst were presented in Fig. 4. In natural zeolite FT-IR spectra, the wavelength between 2600 and $3700 \mathrm{~cm}^{-1}$ corresponds to the $\mathrm{OH}$ bond stretching vibration of $\mathrm{H}_{2} \mathrm{O}$ is clearly visible. The peak between 1000 and $1300 \mathrm{~cm}^{-1}$ indicate the asymmetric Si-O-Si. The Si-O-Si bending bond occurs at a wavelength of $458 \mathrm{~cm}^{-1}$. Meanwhile, the peak of 757 and $811 \mathrm{~cm}^{-1}$ shows the symmetric vibration of $\mathrm{Si}-\mathrm{O}-\mathrm{Si}$ bonds. In the zirconia catalyst spectra, the $\mathrm{OH}$ stretching vibration of water was at $3426 \mathrm{~cm}^{-1}$. The wavelength number at 1090 and 1216 $\mathrm{cm}^{-1}$ correspond to asymmetric Si-O-Si vibrations which are seen to reduced in intensity compared to activated natural zeolite. The appearance of the bands between from The T-O-T bonds ( $\mathrm{T}=\mathrm{Si}$ or $\mathrm{Al}$ ) appears at 1088 and $1230 \mathrm{~cm}^{-1}$ which correspond to $\mathrm{Si}-\mathrm{OH}$ vibrations. The intensity of this band tends to increase when several metals are incorporated of the metals into the surface of materials.

\section{Activity Test \\ Mole Ratio Effect}

The important parameter that affects the conversion of FFAs is the oil to methanol mole ratio. Mole ratio is the ratio between the mole number of oil to the mole number of alcohol that used in the experiment. Theoretically, the FFAs esterification reaction requires one mole of alcohol for each mole of oil that reacted. However, in practice, the mole ratio must be provided more than the stoichiometric ratio requirement to drive the equilibrium to the methyl ester product. The POS to methanol mole ratio is varied at a number value of 1:4, 1:6, 1:8, and 1:10, while the reaction was kept constant at the identical operating conditions (reaction temperature of $60^{\circ} \mathrm{C}$, catalyst amount of $5 \%$ wt. of oil, dan reaction time of 4 h). It was concluded that an enhancement of methanol mole number leads to an increasing of conversion of FFAs as shown in Fig. 5. Initially, the FFA conversion was obtained at $67.2 \%$ as the POS to methanol mole ratio was 1:4. Furthermore, the FFA conversion increased from $77.3 \%$ to $80.7 \%$ at the POS to methanol mole ratio of 1:6 to $1: 8$ molar ratio respectively. Furthermore, the FFA conversion increases to $84.22 \%$ in the oil to methanol mole ratio of 1:10.

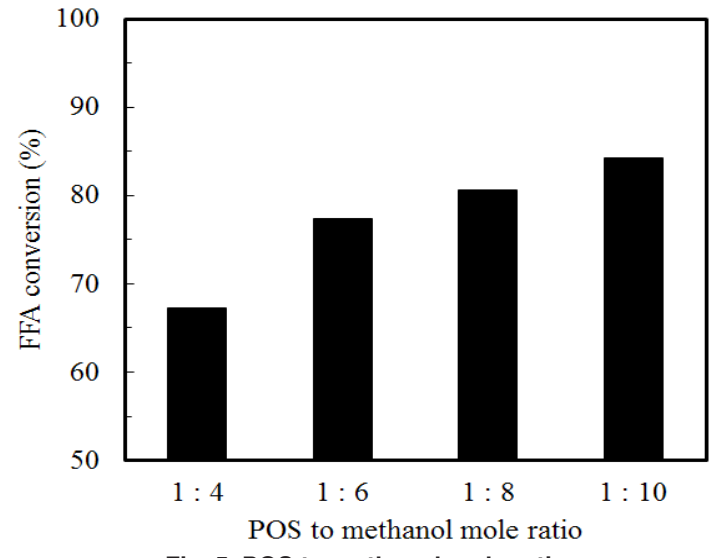

Fig. 5. POS to methanol mole ratio

\section{Reaction Temperature Effect}

The reaction temperature effect on the conversion of FFAs was investigated by conducting esterification reactions at different temperatures $\left(35,45,55\right.$, and $\left.65^{\circ} \mathrm{C}\right)$, while the POS to methanol mole ratio and catalyst amount was maintained constantly at $1: 10$ and $10 \mathrm{wt}$ \% of POS, respectively. Fig. 6 exhibits the conversion of FFAs at different reaction temperatures. As illustrated in Fig. 6, the results indicated that the reaction temperatures had an effect on FFA conversion during the esterification reaction. The FFA conversion achieves at $64.2 \%$ after time reaction of $2 \mathrm{~h}$ and reaction temperature of $35^{\circ} \mathrm{C}$. Subsequently, the FFA conversion reached to 74.4 and $80.4 \%$ at reaction temperature of 45 and $55^{\circ} \mathrm{C}$, respectfully. Noteworthy, the maximum FFA conversion acquired at $84.2 \%$ when the reaction temperature of $65^{\circ} \mathrm{C}$. It was can be summarized that the FFA conversion on the product increased with the rising of reaction temperatures. The high of FFAs conversion was due to the acceleration of reaction rate which caused more methyl ester produced. The solubility of the oil in methanol will increase at higher temperatures, thus the problems associated with mass transfer limits will be reduced.

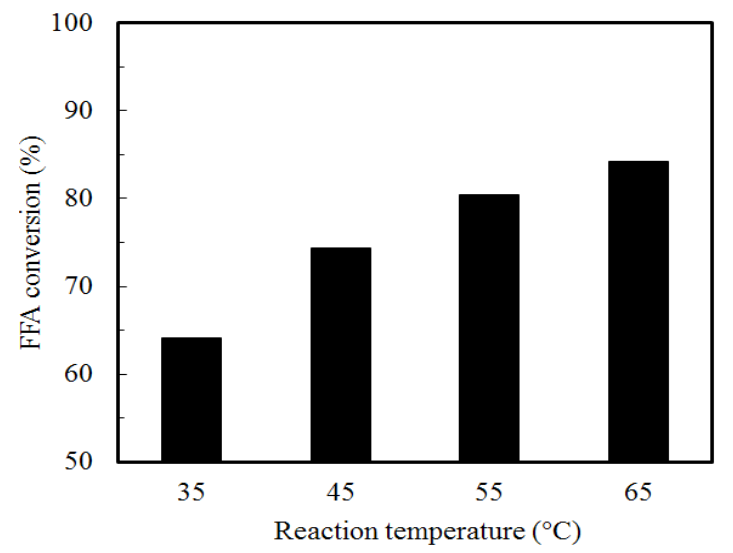

Fig. 6. POS to methanol mole ratio 


\section{Catalyst Amount Effect}

The catalyst amount is the important parameter in the biodiesel production using a heterogeneous catalyst. The heterogeneous catalysts preferably are employed due to easy separation from product mixture and regenerable. The appropriate catalyst amount to achieve maximum FFA conversion is investigated by varying in the range of $2.5,5,7.5$ and 10 wt.\% of POS. The percentage values were the mass fractions of the POS applied to the reactant mixture. The experiments were conducted with a reaction temperature of $60^{\circ} \mathrm{C}$ and a fixed POS to methanol mole ratio of $1: 10$, respectively. The conversion of FFAs at different reaction temperatures was presented in Figure 7.

Increasing the catalyst amount from 2.5 to 5 wt. \% of POS increased the FFA conversion from 66.9 to $72.3 \%$. Among the catalyst amount variations studied, the highest FFA conversion was $84.2 \%$ at the catalyst amount of 10 wt. $\%$ of POS. The results exhibited the improvement of FFA conversion when the catalyst amount was increased. The increase in FFA conversion is due to the addition of catalysts amount will lead the more of active sites available in catalyst surface. Hence, the optimum amount for FFA conversion is considered at the catalyst amount of 10 wt. \% of POS.

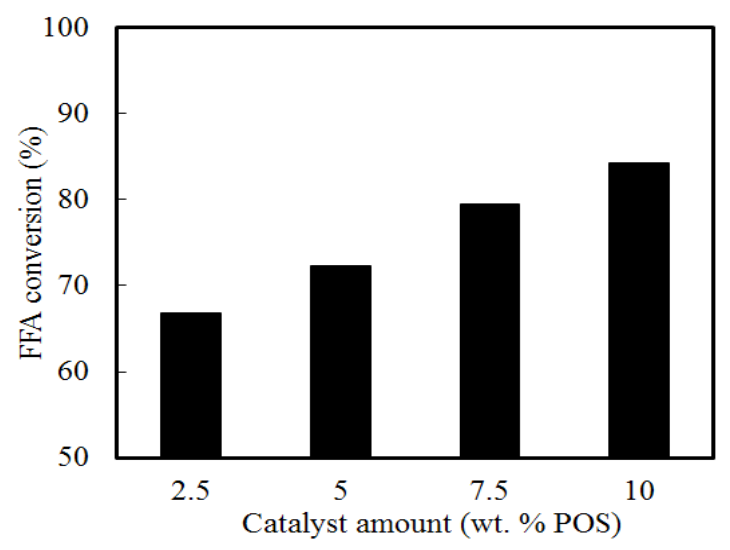

Fig. 7. POS to methanol mole ratio

\section{Catalyst Reusability}

The catalyst performance associated with repeated use is investigated by subsequent reaction cycles. Prior to reuse, the catalysts were activated by washing them with hexane to remove residual oil and impurities on the catalyst surface. After that, the catalysts were further dried in the oven at $120^{\circ} \mathrm{C}$ in the oven for 4 hours. Then the catalysts were applied for an esterification reaction under the identical reaction conditions as before. The result of reusability test is depicted in Fig. 8. As shown in Fig. 8, the FFA conversion was reduced in the second and third consecutive reactions.

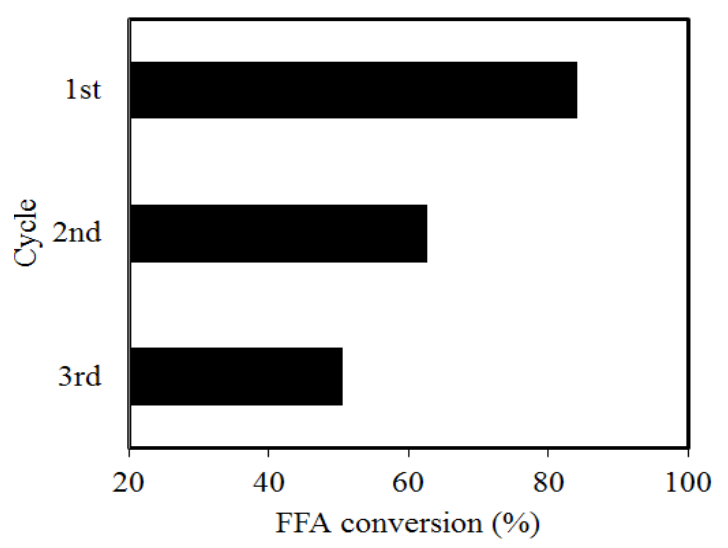

Fig. 8. POS to methanol mole ratio CONCLUSION

The biodiesel production from Palm oil sludge (POS) containing high free fatty acids (FFA) using Zirconia natural zeolite catalyst was studied. The catalyst was prepared by impregnation of Zirconia metal on the activated natural zeolite surface. The physico-chemical characteristics of catalysts were analyzed in term of porosity analysis, XRD, elemental composition and FTIR. The optimum operation conditions of esterification reaction was POS to methanol mole ratio of 1:10, catalyst amount of $10 \mathrm{wt} . \%$ POS, and reaction temperature of $65^{\circ} \mathrm{C}$. At this optimum condition, the FFA conversion achieves $84.2 \%$.

\section{ACKNOWLEDGEMENT}

Funding for this research was provided by the Direktorat Jenderal Penguatan Riset dan Pengembangan, Direktorat Riset dan Pengabdian Masyarakat, Kemenristekdikti, Indonesia for financial support through the Penelitian Strategis Nasional Institusi 2018 research grant.

\section{REFERENCES}

1. Bhandari, R.; Volli, V.; Purkait, M. K., J. 2. Environ. Chem. Eng., 2015, 3, 906-914.
Sirajuddin, M.; Tariq, M.; Ali, S., J. Organomet. Chem., 2015, 779, 30-38. 
3. Abo-Dief, H. M.; Emam, A. S.; Abualnaja; K. M.; Mohamed, A. T., Orient. J. Chem., 2018, 34, 1011-1015.

4. Kadapure, S. A.; Kirti, P.; Singh, S.; Kokatnur, S.; Hiremath, N.; Variar, A.; Shaikh, S.; Chittaragi, R., Int. J. Sustain. Eng., 2017, 1-6.

5. Nurcahyo, I. F.; Wijaya, K.; Triyono; Budiman, A.; Taufiq-Yap, Y. H., Orient. J. Chem., 2018, 34, 750-756.

6. Qiu, T.; Guo, X.; Yang, J.; Zhou, L.; Li, L.;Wang, H.; Niu, Y., Chem. Eng. J., 2016, 296, 71-78.

7. Feyzi, M.; Hosseini, N.; Yaghobi, N.; Ezzati, R., Chem. Phys. Lett., 2017, 677, 19-29.

8. Maleki H.; Kazemeini M.; Bastan F., Chem. Eng. Technol., 2017, 40, 1923-1930.

9. Hidayat, A.; Mukti, N. I. F.; Handoko, B.; Sutrisno, B., Int. J. Tech., 2018, 9, 400-411.

10. Augustia, V. A. S.; Djalal, R. A.; Sutrisno, B.; Hidayat, A., IOP Conf. Ser. Mater. Sci. Eng., 2018, 105(1),012065.

11. Hidayat, A.; Sutrisno, B., AIP Conf. Proc., 2017, 1803, 020046.

12. Hidayat, A.; Sutrisno, B., AIP Conf. Proc., 2017, 1840, 050001.

13. Pradana, Y. S.; Hidayat, A.; Prasetya, A.; Budiman, A., Defect Diffus. Forum., 2018, 382 DDF, 280-285.

14. Nguyen, H. K. D.; Van Pham, P.; Vo, A. D., J. Porous Mat., 2017, 24, 411-419.

15. Raia, R. Z.; da Silva, L. S.; Marcucci, S. M. P.; Arroyo, P. A., Catal. Today., 2017, 289, 105-114.

16. Saravanan, K.; Tyagi, B.; Shukla, R. S.; Bajaj, H. C., Appl. Catal. B Environ., 2015, 172-173, 108-115.

17. Prinsen, P.; Luque, R.; González-Arellano, C., Micropor. Mesopor. Mat., 2018, 262, 133-139.

18. Baroi, C.; Dalai, A. K., Appl. Catal. A Gen., 2014, 485, 99-107.

19. Doyle, A.M.;Albayati, T.M.;Abbas, A.S.;Alismaeel, Z.T., Renew. Energ., 2016, 97, 19-23.

20. Purova, R.; Narasimharao, K.; Ahmed, N. S. I.; Al-Thabaiti, S.; Al-Shehri, A.; Mokhtar, M.;
Schwieger, W., J. Mol. Catal. A Chem., 2015, 406, $159-167$.

21. Vieira, S. S.; Magriotis, Z. M.; Santos, N. A. V.; Saczk, A. A.; Hori, C. E.; Arroyo, P. A., Bioresour. Technol., 2013, 133, 248-255.

22. Rezende, M. J. C.; Pinto, A. C., Renew. Energ., 2016, 92, 171-177.

23. Aghabarari, B.; Dorostkar, N., J. Taiwan Inst. Chem. Eng., 2014, 45, 1468-1473.

24. Kanda, L. R. S.; Corazza, M. L.; Zatta, L.; Wypych, F., Fuel., 2017, 193, 265-274.

25. Hykkerud, A.; Marchetti, J. M., Biomass Bioenerg., 2016, 95, 340-343.

26. Ma, G.; Hu, W.; Pei, H.; Jiang, L.; Ji, Y.; Mu R., Environ. Technol. (UK)., 2016, 36, 622-627.

27. Pandiangan, K. D.; Simanjuntak, W.; Rilyanti, M.; Jamarun, N.; Arief, S., Orient. J. Chem., 2017, 33, 2891-2898.

28. Yan, B.; Zhang, Y.; Chen, G.; Shan, R.; Ma, W.; Liu, C., Energ. Convers. Manage., 2016, 130, 156-164.

29. Kaur, M.; Malhotra, R.; Ali, A., Renew. Energ., 2018, 116, 109-119.

30. Nuithitikul, K.; Prasitturattanachai, W.; Hasin, W., Energy Procedia., 2017, 138, 75-80.

31. Mohammed, N. I.; Kabbashi, N. A.; Alam, M. Z.; Mirghani, M. E. S., J. Taiwan Inst. Chem. Eng., 2016, 63, 243-249.

32. Patel, A.; Brahmkhatri, V.; Fuel Process. Technol., 2013, 113, 141-149.

33. Castanheiro, J. E.; Fonseca, I. M.; Ramos, A. M.; Vital, J., Micropor. Mesopor. Mat., 2017, 249, 16-24.

34. Essamlali, Y.; Larzek, M.; Essaid, B.;Zahouily, M., Ind. Eng. Chem. Res., 2017, 56, 5821-5832.

35. Pradana,Y.S.; Hidayat, A.;Prasetya, A.;Budiman, A., Energy Procedia., 2017, 143, 742-747.

36. Hidayat, A.; Rochmadi; Wijaya, K.; Budiman, A., AIP Conf. Proc., 2015, 1699, 050005.

37. Hidayat, A.; Rochmadi; Wijaya, K.; Budiman, A., IOP Conf. Ser. Mater. Sci. Eng., 2016, 105 (1), 012026. 